\title{
Entorn d'unes codolades sobre els actes de fe mallorquins de 1691
}

\section{About some codolades on the Majorcan acts of faith of 1691}

\author{
August Darder Moll \\ Universitat de les Illes Balears \\ eibon_1999@yahoo.com \\ Data de recepció: 21/04/2019 \\ Data d'aceptació: 02/08/2018
}

\section{Resum}

En aquest article analitzem un poema compost en codolades que fou escrit amb motiu dels actes de fe celebrats a Mallorca el 1691, les repercussions dels quals s'han fet sentir a la societat illenca fins ben entrat el segle XX. L'autor de la composició fou un mercedari anomenat Bartomeu Oliver, que suposadament fou testimoni dels esdeveniments i els explicà en vers. En aquest treball fem primer una breu referència al context en el qual es desenvoluparen els processos, a continuació donem algunes dades sobre l'autor i, tot seguit, ens centrem en les característiques del poema, tant formals com de contingut. Ens proposem mostrar, mitjançant l'anàlisi de l'obra, la voluntat que tenia l'autor de justificar els fets - posició que no fou l'únic a defensar-i com compongué un poema de lectura fàcil però al mateix temps enginyós que podia resultar entretingut per a bona part de la població del seu temps.

Paraules clau: conversos mallorquins; judaïtzants mallorquins; xuetes; cremadissa de 1691; Inquisició mallorquina.

\begin{abstract}
In this article we analize a poem composed in codolades written on the occasion of the acts of faith celebrated in Majorca in 1691, whose repercussions on the island's society lasted until the twentieth century. The author of the composition was a mercedarian called Bartomeu Oliver, who is supposed to have been an eye witness of the events and explained them in verse. In this paper we make first a brief reference to the context in which the action took place, then we give some data about the author, and at once we focuse on the contextual and formal characteristics of the poem. Our aim is to show, by the analysis of the work, that the purpose of the author was to justify the trials -a position he wasn't the only one to take- and how he composed a poem that was easy to read as well as clever, so that it could entertain most of the population of his time.
\end{abstract}

Keywords: Majorcan converts; Majorcan judaizers; xuetes; cremadissa of 1691; Majorcan Inquisition. 



\section{Taula de continguts}

1. Introducció

2. L'autor de les codolades

3. El poema

4. L'estructura subjacent del poema

5. Intenció de l'autor

6. Conclusions

Bibliografia 



\section{Introducció}

Ens proposem parlar d'un poema en codolades escrit pel mercedari Bartomeu Oliver amb motiu dels actes de fe contra judaïtzants que la Inquisició mallorquina dugué a terme el 1691. Aquests fets tenen especial significació per dos motius: d'una banda, la magnitud dels processos i el nombre de condemnats que hi hagué; de l'altra, el punt d'inflexió que van suposar per als descendents dels conversos de Mallorca, que a partir d'aquell any i amb ajut d'algunes disposicions que es van adoptar amb el pas del temps, quedaren assenyalats durant unes quantes centúries -només al darrer quart del segle XX es féu evident que la discriminació havia perdut molta de la seva força-.

Un dels aspectes de l'estigmatització que patiren els processats i els seus descendents fou el qualificatiu de $x$ ueta ${ }^{1}$ que hom els aplicà a partir de la celebració d'uns actes de fe anteriors als que tractem, però amb els quals estan íntimament lligats: el 1679 ja foren reconciliades la majoria de futures víctimes de 1691, i se'ls aplicà aquest mot, que va arrelar i ha perdurat fins al present. Aquest qualificatiu ha estat considerat molt ofensiu, fins al punt que al segle XVIII «ser titllat de xueta era una ofensa imperdonable que exigia públic desagravi, si és que es volia salvar l'honor davant un greuge que semblava el summum de la gosadia més impertinent i que maculava la netedat d'un llinatge» (Riera, 1985: 403).

Hi ha un llibre contemporani dels esdeveniments que tingué molt de ressò -fou publicat el mateix any $1691 \mathrm{i}$ ha estat reeditat diverses vegades fins al segle XX-La Fe Triunfante,

\footnotetext{
1 Segons el Diccionari català-valencià-balear, que per a l'etimologia de la paraula remet a xuetó, aquest darrer mot és «aparentment, derivat dim. de xueta, però probablement el procés ha estat invers: xuetó és deformació vulgar de juetó (forma medieval que significava 'jueu petit', 'fill de jueu', derivada de jueu [...]), i xueta es deu haver format per regressió damunt xuetó. Els etimòlegs havien partit fins ara de la base de considerar xueta o xuieta com a derivat de xuia, 'cansalada', i es fundaven en els casos que ocorren en diverses llengües, de donar-se als jueus noms ofensius que signifiquen 'porc' o 'carn de porc'; així ho havien admès Eguílaz Glos. 377, Spitzer (BDC, XI, 134) i Corominas DECast, s. v. marrano. A Mallorca és general la creença en aquest origen xueta <xuia, i la gent l'explica dient que els jueus relapses i reconvertits, durant les primeres generacions de llur estigmatització, menjaven xuia (cansalada) públicament per fer veure la realitat de llur conversió al cristianisme. Però davant el gran ús i gairebé predomini de la forma xuetó damunt xueta, sembla més probable que el vertader origen hagi estat juetó (dim. de $j u e u$ ) i que la $j$ s'hagi convertit en $x$ secundàriament, per analogia de $x u i a$, per haver estat relacionat el mot amb la cansalada per aquella tendència general a indagar si els conversos menjaven porquim. De xuetó s'hauria format xueta per una simple regressió, afavorida per la circumstància que la forma xuieta resultava més acostada a xuia que xuetó» (s. v. xuetó).
} 
escrit pel jesuïta Francesc Garau, testimoni dels fets, als quals prengué part com a confessor d'alguns dels reus. Aquesta obra ha quedat indissolublement lligada a aquests successos i les seves conseqüències per la cruesa que demostra en la descripció dels fets en general i de les execucions en particular, i se li atribueix part de responsabilitat en l'estigmatització de la gent «del Carrer»².

\section{L'autor de les codolades}

Les principals dades que tenim sobre la seva vida les dóna l'erudit Joaquim Maria Bover a la seva obra Biblioteca de escritores baleares (1868): Oliver era natural de Mallorca, concretament de Campos, on nasqué en data desconeguda. Els seus pares eren Antoni Oliver i Francisca Gazà, dels quals hem trobat informació en un llibre de concessos on, l'any 1605, Antoni i una sèrie de testimonis declaren per demostrar que el primer és fadrí: gràcies a aquest document sabem que Oliver pare era d'origen francès, concretament «de vila francha del duch de Savoia ${ }^{3}$. El 1637, Bartomeu Oliver professà com a mercedari a Ciutat. Fou doctor en teologia $\mathrm{i}$ exercí de catedràtic de teologia lul·liana a la Universitat de Mallorca; també obtingué un grau de Presentat de justícia. A més de les codolades, Bover diu que també escriví un Manuale Theologiae Lullianae que romangué manuscrit (Bover, 1975: II, s. v. Oliver [Bartolomé]). A banda d'aquestes informacions, hem trobat algunes altres referències, com a l'obra de Tobar-Díez Historia del convento de Nuestra Señora de la Merced, on hi ha un llistat de «Religiosos ejemplares»; del nostre autor, simplement en diu: «El P. Presentado Fray Bartolomé Oliver, celebre $[$ sic] en la predicación; Doctor y Catedrático perpetuo en la Universidad de Mallorca» (1968: 21); també l'hem localitzat a l'obra Biblioteca mercedaria, de José Antonio Garí, però la informació que dóna aquest autor està agafada de Bover, com ell mateix indica (1875: 208).Altres dades que

2 «Els del Carrer» era una manera de referir-se als descendents dels jueus conversos mallorquins. Hi ha diferents teories sobre l'origen d'aquesta denominació: Abulafia creu que es deu al fet que molts descendents de conversos vivien al carrer de l'Argenteria (1996: 103). Val a dir que no només habitaven aquest carrer, sinó tota una barriada, i que la resta de ciutadans sovint es referien a ells com a individus «del carrer del Segell». En tot cas, el procés que hauria donat «del Carrer» és el mateix en ambdós casos. Una opinió que contrasta amb l'anterior és la de Montaner, que considera que Call s'hauria traduït erròniament per Calle, i de la forma castellana «de la Calle» s'hauria derivat «del Carrer» (2013: 114).

3 Arxiu Diocesà de Mallorca, Concessos LXI 1605-1606, ff. 130v-131v; la cita es troba al f. 131v. 
hem pogut arreplegar: a un sermó imprès que es féu el 3 de gener de 1666 en honor a la mort de Felip IV, a la pàgina 3 hi ha una censura escrita per Oliver, en castellà: «Aprovacion y censura del M. R. P. M. Fr. Bartholome Oliver, de la Sagrada Religion de N. S. de la Merçed, Redempcion de Cautivos, Cathedratico de la Vnivercidad de Mallorca» ${ }^{4}$; i també apareix esmentat en uns manuscrits realitzats amb motiu de visites pastorals al convent de la Mercè: a la visita del 7 de juny de 1637 Bartomeu Oliver consta com a novici5; a la que es dugué a terme el 19 de maig de 1639, es troba entre els «Legos Profesos» ${ }^{6}$; dia 8 d'agost de 1654 hi ha una descripció de la seva cel·la i sembla que ja consta com a presentat ${ }^{7}$; a les visites de 25 de juny a 6 de juliol de 1660 i de 28-30 d'abril de 1665 és qualificat de «M» $\mathrm{i} « \mathrm{M}^{\circ} »$, respectivament, de manera que ja devia ser mestre ${ }^{8}$.

\section{El poema}

L'única versió que coneixem de les codolades és una còpia realitzada per J. M. Bover que es troba manuscrita al tom XVIII (1860) de les seves Misceláneas históricas ${ }^{9}$. Francesc Riera i Montserrat el reproduí a partir de Bover a la seva obra Lluites antixuetes en el segle XVIII (1973: 181-191). No ens ha arribat cap exemplar que es remunti a l'època dels fets. En conseqüència, hem partit d'aquest testimoni per dur a terme el nostre estudi. El poema no té títol, però Bover l'encapçalà amb les següents paraules: «Autos de fe celebrados por la Inquisición de Mallorca en los últimos años del siglo XVII. Descritos en tres codoladas por Bartolomé Oliver, natural de Campos, que asistió a ellos» ${ }^{10}$.

\footnotetext{
4 L'exemplar que hem consultat es troba a la Biblioteca Lluís Alemany de Palma (Consell de Mallorca).

$5 \quad$ "Libro de Visitas [...]", a l’Arxiu del Regne de Mallorca (AH C 1269; 37v, 39r).

$6 \quad$ Ibid., 56 r.

7 Ibid., 83bisr, 87r. Si diem «sembla» és perquè el càrrec està designat amb una abreviatura i no estem completament segurs del significat.

$8 \quad$ Ibid., $96 \mathrm{r}, 104 \mathrm{v}$.

9 Misceláneas, tom XVIII. Es troben a la Biblioteca Bartomeu March de Palma.

10 Ibid., 239r. Aquesta informació apareix als últims versos del poema (975-989) i al vers 157 posa l'any que els judaïtzants foren empresonats -1688-; per tant, «en los últimos años del siglo XVII». Tant si aquest encapçalament és obra de Bover com d'algú altre, no afegeix res de nou, a banda d'una presentació al principi de l'obra.
} 
En estudiar aquest text, ens hem centrat en tres aspectes, dels quals en aquest article només esmentarem els punts més rellevants. Són aquests: a) el context històric; b) l'àmbit formal; c) la intenció de l'autor a l'hora d'escriure el poema.

Entre finals del segle XVI i al llarg dels tres primers quarts del XVII, sense comptar alguns casos ailllats, la Inquisició illenca es va mantenir bastant inactiva pel que fa a la persecució de judaïtzants; concretament, entre 1536 i 1675 a Mallorca ningú fou relaxat per judaïtzar i entre 1583 i 1675 foren molt pocs els reconciliats per aquest motiu (Cortès, 1985: II, 199). El 1673, una sèrie d'acusacions per part de serventes de descendents de conversos (1985: II, 223-224) conduïren als actes de fe de 1679, les penes dels quals consistiren en la confiscació de tots els béns dels processats i la condemna de portar sambenet en públic durant un període determinat de temps (1985: II, 232-237).

El 1688 una part dels habitants del Carrer, sentint-se insegurs, van voler fugir de l'illa. Trobaren passatge en un vaixell anglès -aquest episodi surt al poema d'Oliver-, però un cop embarcats es va desfermar una tempesta que impedí la partida. Els passatgers van haver de tornar a terra i foren arrestats per la Inquisició (Cortès 1985: II, 247). Tot seguit s'inicià un procés que durà tres anys, durant els quals els fugitius frustrats van estar tancats a les presons inquisitorials (1985: II, 249). Al final d'aquest període de temps van tenir lloc els actes de fe de 1691 que Bartomeu Oliver descriu al seu poema, en els quals foren processades 88 persones, de les quals 37 foren executades -tres d'elles cremades vives-, 40 foren penitenciades i 11 foren representades en estàtua perquè havien mort o fugit.

El text es divideix en tres parts: a la primera s'explica com judaïtzaren els descendents de conversos i es narren els dos primers actes de fe dels quatre que hi va haver el 1691 -Bover (1975: II, s. v. Oliver, [Bartolomé]) passa per alt aquest segon aspecte, omissió que s'ha repetit a la informació que sobre aquesta obra donen el Diccionari de la Literatura Catalana (s. v. Oliver i Gazà, Bartomeu) i la Gran Enciclopèdia Catalana (s. v. Oliver i Gazà, Bartomeu)-; també comenta Bover (1975: II) que aquest primer fragment «trata del origen de los judíos en Mallorca, pondera sus crímenes y cuenta lo que sucedió cuando fueron delatados al tribunal del santo oficio». En realitat, Oliver diu que contarà la història dels jueus (vv. 3-4), però el que 
fa és enumerar tota una sèrie de comportaments que proven que els descendents de conversos judaïtzaven, sense que aquests exemples impliquin cap retrocés històric en el temps, de manera que no tracta l'origen dels jueus, tot i que així ho afirmen no només Bover, sinó també el Diccionari de la Literatura Catalana i la Gran Enciclopèdia Catalana, i aquests darrers sense esmentar l'enumeració dels «crims» comesos pels judaïtzants, que sí que surten al poema. La segona i tercera parts són la descripció del tercer i quart actes de fe, respectivament. Els processos tingueren 1 loc els dies 7 de març, 1 de maig, 6 de maig i 2 de juliol ${ }^{11}$; però Oliver diu que el quart se celebrà el 28 de juny, informació que fou recollida per Bover (1975: II, s. v. Oliver [Bartolomé]) i, posteriorment, per la Gran Enciclopèdia Catalana i el Diccionari de la Literatura Catalana. La composició acaba amb una mica d'informació sobre l'autor: el seu nom, algunes dades biogràfiques i l'afirmació d'haver assistit als actes que acaba de descriure. El poema està format per 989 versos en total; la primera part en té 502 - Bover (1975: II) diu que en té 480-; la segona en té 307, i la tercera 180 - 108 segons Bover-. Pel que fa a la distribució, la primera part ocupa els versos 1-502, la segona els 503-809 i la tercera va del 810 al 989; la informació biogràfica ja esmentada ocupa els versos 975-989.

Ja hem dit que el poema està escrit en forma de codolades - està constituït per heptasíl·labs i tetrasíl·labs que rimen formant parelles-; tot i així, hi ha alguns versos, pocs, que tenen 8 síl·labes i d'altres que en tenen 5 . Sobre aquest punt, tinguem en compte que treballem amb una còpia d'època molt posterior; potser hi ha errors de transcripció, tot i que sense poder contrastar el text no podem afirmar res amb seguretat.

\footnotetext{
11 La comprovació de la data correcta fou una mica complexa, perquè hi ha una errada a La Fe Triunfante, que dóna dues dates diferents per al quart acte. El títol que apareix a l'explicació dels fets és: «Auto cuarto y ultimo de esta complicidad celebrado en Mallorca a 2 de junio de 1691» (1984: 57) i, més endavant, «Reos relajados, reconciliados y penitenciados, que salieron en persona y en estatua al cuarto auto el dia 2 de julio de 1691» (1984: 60). Aquesta errada apareix a totes les edicions: Garau, 1691: 69, 73; 1755: 104, 111; 1931: 79, 82; 1931: 79, 83 aquestes són les que dóna Palau (1990: VI, s. v. Garau [P. Francisco]) i que nosaltres hem vist; diu Muntaner que «[s] egons l'investigador i bibliòfil Antoni Sastre de Sa Torreta encara existiria una altra edició de "La Fe triunfante..." publicada a la "Biblioteca de la Inquisición" Madrid 1930 (?) i que ens ha estat impossible trobar» (1984: LIV)-. La incertesa sobre el dia concret ha provocat que els autors posteriors situïn l'acte el 2 de juny o el 2 de juliol, sense que quedi clara la data: Cortès (1985: 267) i Selke (1972: 238, n. 22) diuen que fou el dos de juny, mentre que Perdigó (1946: 274-275) dóna el dos de juliol però a la «Nota preliminar» (1946: 11) diu que fou el juny. En vista d'això, vam recórrer a alguns dietaristes contemporanis dels fets, segons els quals aquests tingueren lloc el 2 de juliol (Mut, 1883: X, 285; Matheu, 1939: 159).
} 
La rima és principalment consonant, però també n'hi ha d'assonant, 107 casos en total. Hi ha molta rima fàcil: vint-i-quatre entre infinitius, vint-i-cinc entre participis, cinc entre formes de futur, quaranta entre formes d'imperfet, vint-i-quatre entre formes de perfet simple, dues entre formes de present de subjuntiu, vuit entre formes d'imperfet de subjuntiu i dues entre formes de present. Entre mots no verbals només trobem rima fàcil en dues ocasions: entre adverbis: detestable / abominable (vv. 52-53) i entre pronoms: exhortant-los / convertir-los (vv. 618-619).

Hi ha almenys tres casos de rima falsa, molt comuna en textos poètics de l'edat moderna: jueus / meus (vv. 4-5); meus / jueus (vv. 54-55, 122-123, 911-912); seus / jueus (vv. 806-807).

Hi ha tant rima femenina com masculina, però no presenten una distribució homogènia. En total hi ha 602 versos masculins i 387 femenins.

La darrera part del poema, que comprèn els versos 975-989, ens proporciona una mica d'informació sobre l'autor ${ }^{12}$ :

De Campos és natural
el orador,
el qual és mereixedor
de ser nombrat
amb nom d'aquell escorxat
sant de honor;
per armes lo Inquisidor
té son llinatge,
i perquè d'aquest ${ }^{13}$ imatge
historiar
punt d'honor li va tocar,
perquè present
sempre estigué al turment,
d'esta memòria
Déu mos don la santa glòria.

Bover, que no valora gens positivament aquest autor degut al tema que tracta i la manera com ho fa ( $c f$. Bover, 1975: II), diu que és ben bo de veure quin és el nom que hi ha amagat al text:

12 Quan a l'article transcrivim fragments del poema, ho fem seguint la normativa actual, però es poden donar casos que no hem alterat per qüestió de mètrica, com per exemple «sant de honor» (v. 980), que ha de tenir quatre síl·labes i per això no l'hem apostrofat.

13 Segons el Diccionari català-valencià-balear, vulgarment el mot imatge pot ser masculí (s. v. imatge). 
[...] aquell escorxat

sant de honor

és sant Bartomeu, i el llinatge la branca d'olivera, o sigui Oliver. Bover (1975: II) afegeix:

El poeta, al parecer, ya que no conocía la virtud de la caridad cristiana, como lo prueba al enseñarse [sic] de un modo furibundo contra el prójimo, estuvo dotado de una modestia muy singular, pues ocultando su nombre, lo hace tras de un velo tan trasparente que únicamente los ciegos podrán dejar de descubrirlo en su composicion, pero los que tenemos vista, al leer la especie de enigma con que termina su grande obra, vemos en ella estampado el nombre de Bartolomé Oliver, como lo verán también nuestros lectores en estos versos $[\ldots]$.

\section{L'estructura subjacent del poema}

Una altra dada que ens dóna Bover sobre Oliver és que «se distinguió en el púlpito por su elocuencia» (Bover, 1975: II), i les característiques del poema ens fan pensar que estava redactat per ser llegit en veu alta. Per fer aquesta afirmació ens basem en: a) la possibilitat de dividir el text en diversos apartats, al marge de les tres parts que l'autor estableix clarament; i b) la presència de figures retòriques adequades a l'oratòria.

En principi, hem pogut establir quatre parts diferenciades: exordi, exposició, argumentació i epíleg. A la primera, que abasta els versos 1-13, l'autor fa saber de què parlarà i mira de predisposar favorablement l'auditori:

\footnotetext{
El nom de Déu invocant començaré, i la història contaré de los jueus i confio, germans meus, que supliran les faltes que trobaran en est tractat (vv. 1-8).
}

Continua amb l'exposició (vv. 14-126), on enumera els delictes comesos pels reus i en dóna exemples: fer festa el dissabte, blasfemar, negar la Immaculada Concepció i la Trinitat, entre altres. Segueix amb l'argumentació (vv. 127-909), on fa una relació dels actes de fe amb 
freqüents referències a Déu. Finalment hi hauria l'epíleg (vv. 910-974), on Oliver fa un resum dels esdeveniments i demana disculpes pels errors que hagi pogut cometre.

Entre els recursos usats al llarg del poema que hom pot relacionar amb l'oratòria, trobem l'estratègia d'enumerar delictes que comunament s'atribuïen als judaïtzants per, a continuació, donar-ne exemples concrets. Per entendre el crèdit que mereix la informació que dóna el text hem de tenir en compte que els lectors o els oients possiblement assistiren als fets o, com a mínim, en tenien notícia i sabien què s'havia esdevingut. Per tant, com ja hem dit, Oliver fa acusacions generals que la gent coneixia i després les justifica amb la menció d'actes determinats que no devien ser, tampoc, desconeguts del poble; però potser es va permetre alguna llicència: per exemple, diu que els habitants del Carrer fan festa el dissabte, cosa que suposa una acusació comuna contra judaïtzants $i$, tot seguit, esmenta un exemple concret que ho demostraria ${ }^{14}$. Segons la manera d'exposar els successos, de vegades poden semblar més greus del que foren o, simplement, donar la impressió que obeeixen a una intenció que no hi havia. De fet, a tot el poema assistim a un procés de culpabilització no mancat de subtilesa que es manifesta, al marge de les acusacions directes, en la designació dels processats com «jueus» o «judios» i altres qualificatius, tant referits a les persones mateixes com a les seves accions: «pecat» (v. 9), «error» (vv. 32, 348), «malícia» (vv. 257, 545) -i la variant fonètica malici, segons la pronúncia mallorquina (vv. 21, 594, 626)-, «abominable» (v. 53), «mala casta» (v. 60), «infeels» (v. 84)...

\footnotetext{
14 En aquest cas suposem que l'exemple és inventat, perquè resulta còmic i tot:

[...] un cert dia

una xinxa una tenia

sobre sa manta,

i veent, una altra, brutor tanta,

sa ma allargà

sols per poder-la-hi tomar;

i amb ràbia quan ho veé,

sa de sa xinxa digué

que la deixàs,

que el dissabte no trencàs (vv. 34-43).
}

Així i tot, altres casos que al principi creguérem inventats vam descobrir que tenien una base real, com el d'una dona que segons Oliver confessà que per no dir Maria deien Burballa; una afirmació així, que sembla ridícula, es correspon en part amb la realitat -la diferència rau en el nom utilitzat-: segons la declaració d'una de les processades, «evitaban 'tomar en la boca' los nombres sagrados de los cristianos», de manera que «quando se ofreçía nombrar a Jesuchristo Nuestro Señor o a la Virgen Santíssima, los nombravan con el nombre de Juan Peroni» (Selke, 1972: 153). 
aquesta llista encara es podria allargar. Oliver també fa servir els coneixements que els lectors tenen dels fets per donar a entendre que el que ell explica ho sap tothom i, per tant, és veritat:

altres [judaïtzants] usaren de l'art que tots bé saben (vv. 137-138);

a luego fonc declarat, com tots bé saben (vv. 858-859).

Un altre exemple de recurs retòric el tenim en les preguntes que el poeta llança i respon ell mateix:

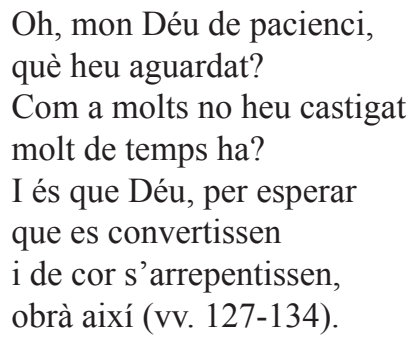

Preguntes i respostes d'aquest estil vénen a ser una justificació dels processos inquisitorials, ja que es dóna a entendre que són producte de la voluntat divina. Les referències a Déu no es limiten a aquest tipus de preguntes:

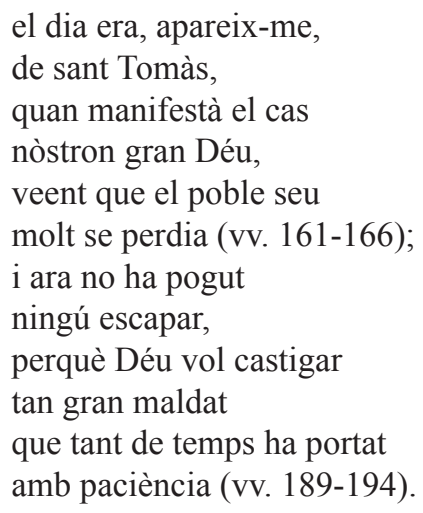

També hi ha referències a l'infern, on han anat els que no s'han volgut penedir:

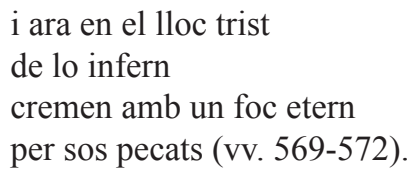


Una altra figura que apareix amb freqüència és l'apòstrofe. En total n'hi ha $22 \mathrm{i}$ es poden agrupar segons el destinatari: 3 van dirigits a Déu i la resta als lectors o oients. Dins aquest darrer grup, Oliver utilitza principalment dos qualificatius per designar els receptors, amb variants en cada cas: germans i cristians. La primera apareix amb més freqüència i presenta formes com «germans meus» (v. 5), «germanets meus» (vv. 54, 484), «mos germans» (v. 610), i simplement «germans» (vv. 739, 765, 799, 960). La segona forma apareix com «cristians» (v. 519) i «cristians meus» (vv. 122, 911). També hi ha alguns casos en què el subjecte se sobreentén: «mirau» (v. 69), i un altre que ofereix diferents variants a partir del mateix esquema: «puis heu de creure» (v. 322), «perquè heu de creure» (vv. 352, 534, 612, 712), «i heu de creure» (vv. 768, 877). Aquesta expressió apareix fins a set cops i serveix per augmentar la impressió de gravetat dels fets. Pel que fa a les mencions de Déu, presenten les formes següents: «mon Déu de pacienci» (v. 127), «mon Déu etern» (v. 597) i «mon Déu omnipotent» (v. 603).

Trobem 17 cops el parèntesi, que podem dividir en explicatiu, quan dóna més informació o aclareix un aspecte, com en

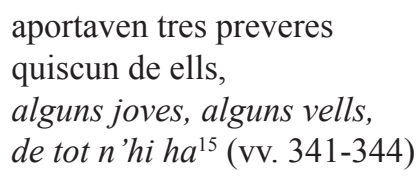

i d'opinió, que majoritàriament es manifesten en forma d'exclamacions: «Oh, mala casta!» (v. 60);

¡Oh, i a quins cruels moments se són posats! (vv. 429-430).

Sovinteja l'ús del patetisme, mitjançant el qual se'ns mostren les reaccions del públic i dels condemnats:

d'aquests seguien darrere, amb gran concòrdia, demanant misericòrdia, cinc o sis hòmens; aprés venien ses dones,

15 Hem posat en cursiva la part que constitueix el parèntesi. 
molt compungides,

qui veent ses seves vides

qui s'acabaven,

misericòrdia clamaven

de bon de veres (vv. 331-340).

Finalment, un altre recurs és donar a entendre que hi ha coses que no diu, de manera que els crims semblen pitjors:

puis aun majors pecats

pas en silenci (vv. 125-126),

diu Oliver quan acaba l'exposició dels «delictes» comesos pels habitants del Carrer.

\section{Intenció de l'autor}

Amb tot el que hem vist, ens sembla prou clar que la voluntat d'Oliver en escriure el poema fou justificar els processos i mostrar la culpabilitat dels reus; al cap i a la fi, la mateixa intenció que tenia Garau en escriure La Fe Triunfante -però hem de tenir en compte que aquesta darrera fou un encàrrec directe de la Inquisició (Montaner, 2013: 120)-. Es tractava de fer propaganda: deixar constància dels fets, exaltar la religió catòlica, denunciar els errors dels judaïtzants i mostrar el càstig que pateixen per la seva actitud. Evidentment, hi ha una diferència considerable entre les dues obres, sobretot en la forma d'expressar-se: Garau escriu en prosa i dóna explicacions llargues i detallades; Oliver escriu en vers i això limita l'aprofundiment en el tema, que és tractat més superficialment, però recorrent sovint a anècdotes.

Com que La Fe Triunfante fou impresa i a més gaudí de recolzament institucional, com hem vist, és natural que tingués un èxit que l'uní als processos de manera indissoluble, mentre que la recepció de les codolades d'Oliver, pel fet de romandre manuscrites, degué ser ben diferent i ens és desconeguda. Donades les característiques del text, és probable que fos llegit en veu alta, cosa que donaria més efecte als recursos oratoris que utilitza. Però aquesta darrera suposició no és més que una hipòtesi de la qual no tenim cap prova. 
Com a mostra de les semblances i diferències entre Garau i Oliver, donarem un fragment de cada una de les obres sobre un mateix esdeveniment, l'intent de fugida de l'illa per part dels habitants del Carrer. Diu Oliver:

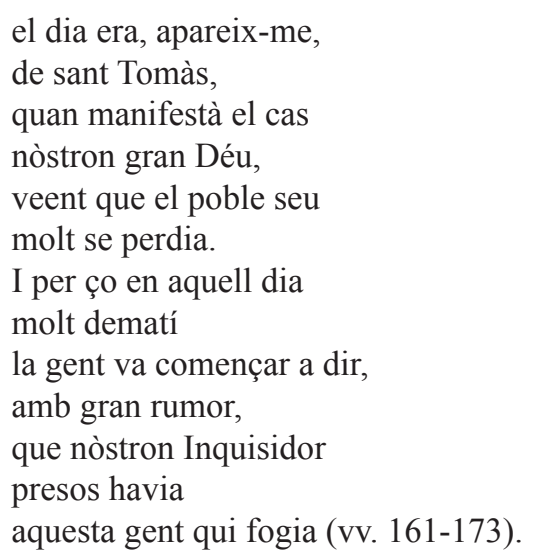

\section{Garau (1984: 21):}

Bien pudiera Dios rigurosamente piadoso dejarles apartar de estos mares y sepultarles después en golfos de agua para eternizar su muerte en las llamas que merecían. Mas los adorables juicios de la Providencia Divina $[. .$.$] a veces se nos dan a venerar dejándose traslucir en la benignidad de sus efectos. Y a la verdad del$ devoto y católico modo de morir de casi todos [...], juzgo se puede piadosamente creer que el embarazarles la fuga fue efecto de la predestinación eterna, que quiso librarles de perderse en el agua para que pereciendo en las llamas se lograran para siempre.

Podem veure la diferència en la manera d'expressar-se, condicionada per les característiques textuals ja esmentades, i la semblança en el raonament: segons aquests autors, els fugitius són capturats per voluntat divina, ja que els costums dels judaïtzants són pecaminosos, com es veu als fragments

[...] el poble seu

molt se perdia

$\mathrm{i}$ «en las llamas que merecían». 


\section{Conclusions}

Com hem vist, les codolades de Bartomeu Oliver constitueixen una justificació dels actes de fe. És per això que ens crida l'atenció que el poema no s'imprimís; hi ha la possibilitat que les autoritats volguessin una versió «oficial», que seria La Fe Triunfante de Garau, però no ho podem saber.

El tema tractat, uns esdeveniments verídics ocorreguts en llocs i dates ben concrets, fan que puguem considerar el poema una relació de successos en vers. Oliver afirma haver estat testimoni dels fets, però això no és concloent; hem vist que s'equivoca de data quan parla del quart acte de fe, i també hi ha alguna altra divergència amb la informació que dóna Garau. No pensem que aquestes errades i discrepàncies vulguin dir que el nostre autor no fou present als actes que explica; però la seva afirmació d'haver-hi estat s'ha de prendre amb prudència, ja que és un lloc comú a les relacions de successos que l'autor digui que ha vist directament el que explica ${ }^{16}$. Altres característiques que veiem presents al poema les descriu Miralles en parlar sobre unes relacions de successos referides a la Guerra dels Segadors, però que podem aplicar al nostre cas: «aquests poemes volen transmetre un sentiment, pretenen despertar la simpatia del lector, commoure'l i, evidentment, provocar l'adhesió a la causa que hi és narrada: en definitiva, el que busquen és conformar l'opinió pública, decantar-la» (2010: 184). El que vol Oliver és estimular l'animadversió contra els processats i que els càstigs imposats per la Inquisició siguin considerats voluntat divina. Miralles també parla d'aspectes més concrets, com la implicació del lector o la presència de la primera persona del singular per marcar la presència de l'autor (2010: 184-185). Trobem exemples del primer punt quan Oliver demana als oients que «suplesquen» (v. 968) les possibles errades; el segon aspecte també hi és present: «començaré» (v. 2); «contaré» (v. 3); «a tots los he demanat» (v. 967)

Tot plegat, es tractaria de trobar un vehicle senzill per transmetre la informació i recordarla, i una bona solució és integrar-la dins una composició poètica la forma de la qual és d'origen

16 Agraïm aquesta darrera informació a la doctora Eulàlia Miralles. 
popular; i que la visió que s'ofereix dels fets, explicada de manera convenient -amb la informació acuradament seleccionada-, passi a formar part del record d'aquests esdeveniments, que bona part dels contemporanis presenciaren i gairebé tots els mallorquins en degueren sentir a parlar. 


\section{Bibliografia}

Libro de Visitas y mādatos del conto. de nra. Sa. de la Md de Mallca. 1631. Inclou altres anys del segle XVII. Palma: Arxiu del Regne de Mallorca. AH C 1269.

Abulafia, D. (1996). Un emporio mediterráneo. El reino catalán de Mallorca. Palma: Ediciones Omega.

Alcover, A. M. i Moll, F. de B. (1975). Diccionari català-valencià-balear. Volum 10. Palma: Editorial Moll.

Bover, J. M. (1860). Miscelaneas historicas. Recopiladas por individuo de la Academia de Bellas Artes de las Baleares y del Instituto Arqueológico de Roma, XVIII. Son Cotoner. ff. 239r-258r. 18 volums. Palma: Biblioteca Bartomeu Marc. Manuscrit.

Bover, J. M. (1868). Biblioteca de escritores baleares. Palma: Imprenta de P. J. Gelabert. Facs. 97. Volum 2. Barcelona/València: Curial.

Broch, À. (Dir.) (2008). Diccionari de la Literatura Catalana. Barcelona: Enciclopèdia Catalana.

Concessos LXI 1605-1606, ff. 130v-131v. Palma: Arxiu Diocesà de Mallorca.

Cortès, G. (1985). Historia de los judios mallorquines y de sus descendientes cristianos. Volum 2. Palma: Miquel Font.

Fiol, S., Sermón en las Honras que se hizieron en el Real Convento de San Francisco de la Ciudad de Mallorca en la muerte del grande Monarca y Rey de las Españas Philipe Quarto a los 3. de Henero 1666. Predicado por el Reverendo Padre Fray Religioso de la S. Provincia de Mallorca, de la Regular Observancia del Seraphico Padre San Francisco, Diffinidor Habitual. Dedicado al Illustre y Noble Don Iorge de San Iuan y Sureda, Caballero del Habito de San Tiago, Señor de los Lugares y Caballerias de Sonarosa y Ariañy. Con Licencia en Mallorca en la Enprĕta de Pedro Frau Impr. Palma: Biblioteca Lluís Alemany (Consell de Mallorca). Conté la censura de Bartomeu Oliver. 
Garau, F. (1691). La Fee Triunfante en quatro autos celebrados en Mallorca por el Santo Oficio de la Inquisicion en que an salido ochenta, i ocho reos, i de treinta, i siete relaiados solo uvo tres pertinaces. Con licencia en Mallorca en la Emprenta [sic] de la Viuda Guasp. [En línia] Disponible a: <https://books.google.es/ books?id=jrVUyBAT6MsC\&pg=PP4\&dq=la+fee+triunfante\&hl=ca\&sa=X\&redir_ esc $=\mathrm{y} \# \mathrm{v}=$ onepage $\& \mathrm{q}=\mathrm{la} \% 20 \mathrm{fee} \% 20$ triunfante $\& \mathrm{f}=$ false $>$ [Última consulta: $10 / 07 / 17]$.

Garau, F. (1755). La Fee Triunfante en quatro autos celebrados en Mallorca por el Santo Oficio de la Inquisición, en que han salido ochenta y ocho Reos, y de treinta y siete relajados sólo huvo tres pertinaces. Expressada por el R. P. de la Compañía de Jesús, Calificador del Santo Oficio, Rector del Colegio de Monte-Sion, etc. y la dedica a los Ilustres Magníficos Señores Jurados de la Ciudad y Reyno de Mallorca. Mallorca año 1755. En la Oficina de Ignacio Frau, Impressor del Rey Nuestro Señor. Palma: Biblioteca Pública de l'Estat.

Garau, F. (1931). La Fe Triunfante en cuatro autos celebrados en Mallorca por el Santo Oficio de la Inquisición, en que han salido ochenta y ocho reos y de treinta y siete relajados sólo hubo tres pertinaces. Expresada por el R. P. de la Compañía de Jesús, Calificador del Santo Oficio, Examinador Sinodal de este Obispado, Excatedrático de prima de Teología en el Colegio de Barcelona, y hoy Rector del Colegio de Montesión de la misma Compañía y la dedica a los Muy Ilustres Magníficos Señores Jurados de la Ciudad y Reino de Mallorca Establecimiento tipográfico de J. Tous. Palma. Palma: Biblioteca Pública de l'Estat.

Garau, F. (1931). La Fe Triunfante. Imprenta de la Hija de J. Colomar. Palma. Palma: Biblioteca Pública de l'Estat.

Garau, F. (1984). La Fe Triunfante. Pròleg de Llorenç Pérez. Versió i estudi preliminar de Lleonard Muntaner. Palma: Miquel Font.

Garí, J. A. (1875). Biblioteca mercedaria, ó sea escritores de la celeste, real y militar órden de la Merced, redencion de cautivos, con indicacion de susobras, tanto impresas como 
manuscritas, su patria, titulos, dignidades, hechos memorables, época y provincia en que florecieron y murieron. Barcelona: Imprenta de los herederos de la viuda Pla. [En línia] Disponible a: $<$ https://books.google.es/s?id=DhhCqQZaOHsC\&printsec=frontcover\& $\mathrm{dq}=$ biblioteca + mercedaria $\& \mathrm{hl}=\mathrm{ca} \& \mathrm{sa}=\mathrm{X} \&$ redir_esc $=\mathrm{y} \# \mathrm{v}=$ onepage $\& \mathrm{q}=$ biblioteca $\% 20$ mercedaria\&f=false $>$ [Última consulta: 23/05/17]. Biblioteca de Catalunya: Barcelona.

Gran Enciclopèdia Catalana. (1981). Volum 15. Barcelona: Enciclopèdia Catalana.

Matheu i Bonet, J. A. "Llibre de algunes coses de la Ciutat y Regne de Mallorca. Memorias manuscritas de Chirurgià. Compren de 1643 a 1696". ff. 143-145; 150-157; 159160. Palma: Biblioteca Bartomeu March. Manuscrit. Còpia transcrita per Jaume Cirera Prim el 1939.

Miralles, E. (2010). «Poesia i política en la guerra dels Segadors», en Jané (Ed.) Del Tractat dels Pirineus. Generalitat de Catalunya-Museu d'Història de Catalunya: Barcelona. [En línia] Disponible a: <https://s3.amazonaws.com/academia.edu.documents/35242669/ MirallesPoesiapoliticaTP.pdf?AWSAccessKeyId=AKIAIWOWYYGZ2Y53UL3A\&E xpires $=1533286939 \&$ Signature $=$ SSPwvyIYB3aOHBbv\%2ByfyGqLhUbk\%3D\&respo nse-content-disposition $=$ inline $\% 3 \mathrm{~B} \% 20$ filename $\% 3$ DPoesia_i_politica_en_la_guerra_ dels_Seg.pdf> [Última consulta: 03/08/18].

Montaner, P. de (2013). «Los chuetas como segmento escindido de la comunidad judeoconversa de Mallorca», en Pons-Estel, C. (Coord.) La libertad religiosa en España y la Comunidad Judía Balear, pp. 93-155. Madrid: Delta.

Mut, M. (1883). «Memories de lo que es seguirá aquest present any de 1680. Dins Pascual, B. 1883. “Misceláneas” X». 20 volums manuscrits més dos lligalls, pp. 277, 281-285. Palma: Arxiu del Regne de Mallorca.

Palau i Dulcet, A. (1990). Manual del librero hispanoamericano. Bibliografía general española e hispanoamericana desde la invención de la imprenta hasta nuestros tiempos con el valor comercial de los impresos descritos. Volum 28. Barcelona: Librería Palau. 
Perdigó, M. (Ed.) (1946). Inquisición de Mallorca. Reconciliados y relajados 1488-1691. Barcelona. Palma: Biblioteca Pública de l'Estat. Forma part d'una tirada de 200 exemplars no venals; porta el número 128.

Riera, F. (1973). Lluites antixuetes en el segle XVIII. Palma: Editorial Moll.

Riera, F. (1985). La paraula "xueta" com insult greu. Dins Bolletí de la Societat Arqueològica Lul·liana. Revista d'Estudis Històrics, Volum 41, pp. 403-406. Societat Arqueològica Lul·liana: Palma. [En línia] Disponible en: < http://ibdigital.uib.es/greenstone/collect/ bsal/index/assoc/BSAL_198/5_Tom_41.dir/BSAL_1985_Tom_41.pdf> [Última consulta: 07/08/17].

Selke, A. (1972). Los chuetas y la Inquisición. Vida y muerte en el ghetto de Mallorca. "Madrid: Taurus.

Serrà, A. (1987). El teatre burlesc mallorquí, 1701-1850. Barcelona: Curial Edicions Catalans/ Publicacions de 1'Abadia de Montserrat.

Simó, C. (1990). Catàleg dels noticiaris mallorquins (1372-1810). Palma: Societat Arqueològica Lul·liana.

Tobar-Díez, F. (1968). Historia del convento de Nuestra Señora de la Merced. Palma: Trama printing. 